\title{
A construção da trajetória profissional de um sociólogo num contexto de precarização do trabalho: entrevista com Didier Demazière*
}

\author{
Valéria De Bettio Mattos * *
}

Tradução de Anne-Marie Milon Oliveira

Didier Demazière (DD) - Eu sou Didier Demazière, sou sociólogo. Eu sou pesquisador do Centre National de Recherche Scientifique $(\mathrm{CNRS})^{1}$ desde... Entrei em 1992, isso faz quase vinte anos agora, e pertenço ao Centre de Sociologie des Organisations $(\mathrm{CSO})^{2}$ do Institut d'Études Politiques (IEP) 3 desde janeiro de 2010. Faz um ano agora.

Valéria De Bettio Mattos (VM) - Certo. Como foi que você fez a "escolha" da profissão de sociólogo?

DD - Como fiz a escolha? $\mathrm{Na}$ verdade, não fiz exatamente uma escolha. Fiz a escolha de estudar sociologia, isso é verdade.

VM - Foi por isso que fiz o gesto de aspas!

* Entrevista realizada em 9 de fevereiro de 2011, no contexto do projeto de estágio de doutoramento intitulado "Desemprego entre jovens e ampliação da escolarização diante do estreitamento de opções de trabalho” (2010-2011), no Institut d'Études Politiques de Paris (Sciences Po/CNRS), com bolsa do Conselho Nacional de Desenvolvimento Científico e Tecnológico (CNPq), sob supervisão do professor doutor Didier Demazière, presidente da Associação Francesa de Sociologia (AFS).

** Doutora em educação pela Universidade Federal de Santa Catarina (UFSC). Professora da Universidade Federal da Fronteira Sul(UFFS), campus Chapecó/SC. E-mail: valeria. mattos@uffs.edu.br.

1 Centro Nacional de Pesquisa Científica.

2 Centro de Sociologia das Organizações.

3 Instituto de Estudos Políticos, que forma boa parte da elite francesa. Ele é mais conhecido pelo nome de "Sciences Po" ("Ciências Políticas"). 
DD - No ensino médio, fiquei na linha de especialização "filosofia" e tinha, portanto, muito interesse pela filosofia, mas, ao mesmo tempo, pensava comigo mesmo que a filosofia não iria me levar muito longe profissionalmente. Mas não tinha vontade de estudar ciências naturais ou matemáticas. Tampouco queria ensinar, ser professor de ensino médio etc. Adorava história e talvez gostasse mais disso. Daí que li alguns livros de sociologia e de etnologia na biblioteca do colégio e os achei interessantes...

VM - Que idade tinha então?

DD - Tinha, mais ou menos, 16 anos e decidi fazer inscrição na universidade, em antropologia. Além disso, morava no norte da França, em Lille. Na realidade, na universidade de Lille não havia curso de antropologia, só mestrado. Então resolvi estudar sociologia. Fiz matrícula no primeiro ano. Mas realmente preferia ter feito antropologia, arqueologia... Era isso que tinha em mente!

Escolhi a sociologia um pouco por falta de opção; era o que mais se aproximava. $\mathrm{E}$ de fato gostei, muito rapidamente, rapidamente mesmo, fiquei apaixonado. Até hoje me lembro das primeiras aulas! Lembro-me do curso sobre o suicídio, na sociologia, de Durkheim, que adorei. Lembro-me de um curso que tratava do duplo casamento e que foi publicado em artigo, em 1975, na revista Actes de la Recherche en Sciences Sociales, acho eu. O artigo trazia a observação de um casamento em que o casal era de famílias oriundas de meios sociais muito diferentes. $\mathrm{O}$ artigo mostrava como, durante o casamento, as famílias não se misturavam. Uma família operária, uma família burguesa. Então, foi desse negócio, dessas observações que gostei. Foi por isso que me dediquei aos estudos de sociologia. Então, pronto, terminei o primeiro ano, fiz o segundo ano. Tinha bons resultados. Fiz o terceiro e a partir daí continuei, simplesmente.

Uma vez no mestrado, no quarto ano de universidade fiquei insatisfeito... Não da sociologia, mas a nossa universidade era relativamente pequena e queria ter outros professores, outros ensinamentos, outros cursos. Então, procurei inscrever-me na École des Hautes Études em Sciences Sociales $(\text { EHESS })^{5}$ de Paris, mas era tarde e o prazo de inscrição estava encerrado... Então, tentei... Me inscrevi na faculdade de direito, na qual fiz um Diplome d'Études Approfondies (DEA), ${ }^{6}$ ou seja, o quinto ano de ciências políticas. E aí eu descobri outras coisas, notadamente, a história das ideias políticas. Fiz uma monografia sobre os candidatos minoritários das eleições presidenciais da França, isto é, os pequenos candidatos que obtinham uma votação

4 Na França,já no ensino médio, várias linhas de especialização são oferecidas aos alunos. Na época citada por Didier Demazière, eram três: matemáticas elementares, ciências experimentais e filosofia.

5 Escola de Altos Estudos em Ciências Sociais.

6 Diploma de Estudos Aprofundados. 
excessivamente fraca, numa época... Acho que era em 1983. Foi dois anos após as eleições presidenciais de 1981, e eu tinha participado do comitê de apoio de Coluche, um humorista francês que tentou se candidatar à eleição presidencial.

Na minha monografia de ciências políticas, centrava meu interesse nos pequenos candidatos desse tipo. Então, obtive o diploma e no ano seguinte me inscrevi na EHESS, no curso de sociologia. Foi quando fiz um segundo DEA. Depois disso obtive uma bolsa de pesquisa, um financiamento para minha tese de doutorado. Então, me inscrevi no doutorado e pronto, não me questionei para saber se me tornaria ou não um sociólogo. Vamos dizer que isso se fez ao longo dos anos, um diploma atrás do outro.

VM - Já funcionava naquela época a estrutura segundo a qual são três anos de graduação, mais dois anos de mestrado e três de doutorado?

DD - Na realidade não era totalmente assim. Havia um diploma ao final de dois anos, chamado Diplôme d'Études Universitaires Générales (DEUG), ${ }^{7}$ seguido do terceiro ano. Isso constituía a graduação. $O$ quarto ano era de mestrado. $O$ quinto ano de DEA e a seguir era o doutorado. Bom, digamos que com relação ao que temos agora, era mais complexo porque havia um diploma de segundo ano e um diploma de quarto ano que não existem mais hoje. Agora, o terceiro ano é de graduação, o quinto ano de master. Bem, mas, grosso modo, era a mesma coisa. No entanto, com uma diferença no fato de que a maior parte dos estudantes parava no quarto ano, no mestrado; e o DEA, o quinto ano, na realidade, era feito por aqueles que queriam fazer uma tese, porque, naquela época, cursar um quinto ano não apresentava muito interesse se o objetivo fosse ingressar no mercado de trabalho.

$\mathrm{VM}$ - Ou para tornar-se mestre ao final do quarto ano?

DD - Sim, no quarto ano. Mas eu fiz um quinto ano simplesmente porque me interessava. Não tinha um projeto profissional em particular e, então, com o DEA, comecei a lecionar, a assumir turmas de trabalhos dirigidos ${ }^{8}$ na universidade. Então, eu ensinava. Trabalhei um pouco em contratos de pesquisa com docentes; eu não fazia coisas muito importantes: entrevistas, trabalho de campo, mas, enfim, participava de contratos de pesquisa e daí defendi minha tese...

7 Diploma de Estudos Universitários Gerais.

8 Disciplina ministrada por professores assistentes, complementar dos cursos magistrais dados pelos catedráticos. 
VM - E eram em Contrat à Durée Déterminée $(\mathrm{CDD})^{9}$ ou Contrat à Durée Indéterminée $(\mathrm{CDI}) ?^{10}$

DD - Não, eram CDD, nem sequer eram CDI...

VM - Havia um contrato?

DD - Pagavam 200 horas, sequer era mensalizado ou coisas desse tipo. Recebia, por exemplo, por entrevista realizada, com base numa tarifa preestabelecida.

$\mathrm{VM}-\mathrm{E}$ que idade tinha na época?

DD - Tinha 25, 26, 27 anos mais ou menos, e foi um período em que não havia recrutamento na universidade, nem no CNRS, porque após os anos de 1980 a direita voltou ao poder. Mitterrand continuava presidente da República, mas a direita tinha vencido as eleições legislativas, então, era um governo de direita, num contexto de rigor orçamentário. O rigor já tinha sido estabelecido pelo governo de esquerda em 1983 e os subsídios para a universidade e a pesquisa já tinham sido cortados. Quase não havia mais recrutamento. E os docentes, os professores diziam: não procurem fazer carreira na universidade ou no CNRS. Não há cargos, então, procurem emprego em outro lugar.

VM - Como em todo lugar!

DD - Então, esse era o contexto e eu, assim que defendi minha tese, obtive um contrato que era um CDD de três anos no Centre d'Études et de Recherches sur les Qualifications (CEREQ). ${ }^{11}$

VM - Aqui, em Paris?

DD - Sim, o CEREQ estava em Paris naquele momento. Na verdade, ele se mudou um pouco mais tarde para Marselha. Ele estava em Paris; então, obtive esse contrato e isso me permitiu, por um lado, publicar minha tese no mesmo ano, sob forma de um livro, fazer alguns artigos e também lançar um projeto de pesquisa que mais adiante resultou no livro sobre as entrevistas biográficas. Isso me permitiu, em primeiro lugar, valorizar minha tese, cujo objeto era o desemprego e o modo

9 Contrato de Duração Determinada, cujo final é estipulado desde o início.

10 Contrato de Duração Indeterminada, ou seja, o final do contrato é aberto.

11 Centro de Estudos e de Pesquisas sobre as Qualificações. 
como os desempregados eram recebidos e acompanhados na Agence Nacional pour l'Emploi (ANPE). ${ }^{12}$

Estava no CEREQ, mas não queria permanecer lá. Apesar de tudo, para mim era uma instituição, um organismo, que fazia mais estudos que pesquisa. Não imaginava passar a vida lá. Podia recuperar um pouco de margem de manobra para fazer o que queria. E, também, era um contrato de três anos, mesmo que mensalizado etc... Então, me candidatei ao CNRS assim que pude, e aí a mesma coisa: os professores, os docentes universitários, aos quais era necessário pedir cartas de apoio, cartas de recomendação, me disseram: pode tentar, mas não deve contar muito com isso. Creio que havia dois cargos para serem preenchidos naquele ano em nível nacional, e, então, tive a sorte de obter um deles, de ser recrutado imediatamente, já na primeira vez que me candidatei ao CNRS. Então, foi isso, um pouco inesperado, mas bom.

$\mathrm{VM}$ - Às vezes isso acontece!

DD - É isso aí... E, então, a partir disso me tornei pesquisador do CNRS e depois pude desenvolver meus trabalhos com muito mais liberdade.

$\mathrm{VM}-\mathrm{E}$ quando foi, exatamente, que ocorreu seu interesse pelo tema desemprego?

DD - Ocorreu durante minha tese, porque, na verdade, tinha começado uma tese sobre as ciências sociais e a demanda social. Grosso modo, era: "será que os pesquisadores das ciências sociais são independentes, livres de produzir o que têm vontade de produzir segundo as regras deontológicas da sua profissão? Ou será que são obrigados a buscar os contratos que geram financiamentos, colocando-se numa situação de dependência dos meios dos quais provém a encomenda? $\mathrm{E}$, como resultado, será que isso reduz ou não sua liberdade de pesquisadores?”

VM - Isso foi na época da orientação do senhor Dubar?

DD - Não. Tinha feito meu DEA sob a orientação de Paul Henri Chombart de Lauwe, que estava se aposentando e que não aceitava mais orientandos de douto-

12 Agência Nacional para o Emprego. Esta agência era uma instituição pública francesa vinculada ao Ministério da Economia, Indústria e do Emprego, criada em 1967, no governo de Jacques Chirac. Suas atribuições consistiam em centralizar as ofertas e procuras por emprego, realizar estatísticas sobre desempregados em busca de recolocação profissional, por meio da análise de suas experiências pregressas. Em 2008, a ANPE fundiu-se com a rede dos chamados Associations pour l'Emploi dans l'Industrie et le Commerce (ASSEDIC) a fim de formar um serviço público de procura de emprego único, tal como ocorre na Alemanha e mais recentemente na Grã-Bretanha. Essa nova instituição chama-se Polo do Emprego (Pôle Emploi). 
rado. Então, foi de fato sob a orientação do seu sucessor na direção do seu centro de pesquisa, Zdenek Strmiska.

\section{VM - Como? Perdão?}

DD - Zdenek era o seu prenome, era um checo, Zdenek Strmiska. Então, era ele meu orientador de tese e, na realidade, durante a tese, eu... Digamos que tive interrogações, dúvidas sobre o interesse que havia em continuar essa tese, sobretudo nesse contexto, enfim... sob sua orientação. E na realidade retomei o contato, por intermédio de alguém, com Dubar, e naquele momento, em seu laboratório, havia um pesquisador que trabalhava a questão do desemprego e estava assoberbado de trabalho e que recebia demandas por parte da ANPE etc. E, então, Dubar me perguntou se eu queria assumir um dos contratos. Então, pronto!

VM - Interessante, não é?

DD - Sim. Mas eu não tinha um interesse especial pela questão do desemprego. Eu assumi esse contrato, era um contrato curto e, depois, Dubar ficou satisfeito com o que fiz. Discutimos sobre os artigos que eu poderia fazer com base no relatório. E aí ele me incitou a me candidatar a uma licitação que tinha sido aberta para uma pesquisa um pouco mais importante. Depois, isso se tornou o tema da minha tese. Então, me candidatei a essa licitação, mas Dubar não quis ser o diretor científico do projeto. Ele dizia: "todo mundo sabe que não trabalho com a questão do desemprego, isso não faz sentido, eu sou contra os 'falsos' diretores científicos. Então, pronto! Você será o responsável pelo projeto". Mas ele me ajudou a escrevê-lo e obtive o financiamento.

Comecei a desenvolver esse projeto e, no decorrer, Dubar me disse: "Olha só, se você quiser, pode transformar isso numa tese de doutorado. Se fizer questão... se quiser prosseguir com seu tema [anterior], faça sua tese paralelamente, mas, senão, isso pode tornar-se uma tese". Assim, finalmente optei por essa solução, fiz minha tese sobre o desemprego e depois a publiquei muito rapidamente numa coleção que Dubar dirigia e depois fiz artigos e outros livros. Foi assim que me tornei um especialista sobre o desemprego. Cheguei a esse tema por puro acaso, mas, também, isso ocorreu nos anos de 1980, início dos anos de 1990, num momento em que essa era uma questão da maior importância na França.

Naquele momento, começava a existir uma consciência de que o crescimento do desemprego, que tinha iniciado nos anos de 1970-1980, não estava tão perto de terminar, que não havia solução, que estava se tornando um fenômeno estrutural. Havia um interesse, publicações, e me beneficiei um pouquinho dessa conjuntura, 
de certa forma, peculiar. Em consequência, até mesmo do ponto de vista editorial, não tive dificuldades em propor a editores livros sobre esse assunto. Bom, é isso!

VM - Foi naquele momento que vocês desenvolveram juntos o método das entrevistas biográficas?

DD - Isso, de fato, é o resultado de um projeto de pesquisa que eu havia lançado no CEREQ, sobre jovens que tinham dificuldade de inserção; porque eu vinha de pesquisas sobre o desemprego.

O CEREQ trabalhava a questão da inserção profissional desses jovens que saíam do sistema escolar francês sem nenhum diploma. Eu tinha constituído uma equipe dentro do CEREQ e, ao mesmo tempo, com os laboratórios de pesquisa associados ao CEREQ. Isso durou muito tempo, seminários de análise para explorar essas entrevistas, e, naquele momento, percebemos, eu e Dubar, nos seminários, que tínhamos muita dificuldade no seio da equipe para chegar a um acordo sobre a análise das entrevistas, sobre, grosso modo, algo simples, enfim, elementar na pesquisa: quando se pega uma entrevista, como entendemos o que o jovem que interrogamos quer realmente dizer?

Cada um tinha sua própria interpretação dos discursos, cada um à sua maneira de fato. Então, refletimos que era preciso escrever algo sobre o método, sobre as maneiras de analisar entrevistas, e não, como dizer?... fazer análise sem rigor, projetar nossas categorias de pensamento sobre as entrevistas coletadas. E, então, foi bastante demorado, o tempo necessário para que chegássemos a essa conclusão, o tempo para pensar o que iríamos fazer. Discutindo, nós dizíamos: "pois, isso poderia dar um livro, seria útil colocar isso em discussão na comunidade dos sociólogos!" Então, tudo isso levou tempo, passaram-se alguns anos nesse processo, até que o livro fosse publicado em 1997.

VM - Como foi formado o grupo de discussão entre você e o senhor Dubar para desenvolver o método das entrevistas?

DD - De fato, nesse grupo tínhamos um seminário regular, tentávamos explicitar aos outros pesquisadores a maneira como concebíamos a análise das entrevistas e isso nos levou progressivamente a fazer, em primeiro lugar, um livro. E, depois, então, publicamos esse livro, que se beneficiou de uma visibilidade bastante intensa e rápida.

VM - Isso era, mais especificamente, um pedido do CEREQ?

DD - Era um trabalho que eu tinha começado no interior do CEREQ com financiamentos externos. Eu não sei, mas talvez o CEREQ fosse o principal financiador, 
me parece... Isto é, toda a realização das entrevistas, a montagem dos inquéritos etc., creio que isso foi feito com recursos do CEREQ. Em compensação, um livro mais metodológico não era uma publicação prevista de antemão, foi decidida no decorrer por causa das dificuldades que tínhamos no grupo, para entrar em acordo quanto aos resultados... Quero dizer... como organizávamos a exploração das entrevistas.

VM - Sim, mas era um grupo grande, não era?

DD - Sim, era um grupo de uma dezena de colegas com formações diferentes...

VM - Diferentes opiniões...

DD - É isso! E também experiências diferentes quanto às entrevistas, e, então, a gente comentava, mas, de fato, com as entrevistas, se a gente não tiver um pouco de método, de rigor na maneira de analisar, a gente pode fazer com que as entrevistas digam qualquer coisa.

Com essas reflexões, fomos procurar outros trabalhos, outras pesquisas baseadas em entrevistas. Vimos como os pesquisadores as exploravam, as analisavam. Vimos que... nunca era, ou pelo menos raramente isso era explicitado, e pensamos, para além do círculo do grupo com o qual trabalhávamos, que havia sem dúvida um interesse para a comunidade dos sociólogos em um livro que, de certa maneira... não indicasse o bom método, mas, pelo menos, desse argumentos sobre um método, entre outros possíveis, e, sobretudo, insistisse no fato de que é preciso explicitar o modo como se tratam os dados.

VM - Era uma possibilidade de explicitação?

DD - É isso. Exatamente.

VM - Agora é uma provocação: reli seu livro, faz pelo menos um mês, e então... entendi bem sua explicação sobre a proximidade com Roland Barthes e tomei notas. Havia, duas ou três vezes, a seguinte frase: "esta aproximação [com a análise do discurso] foi feita para evitar alguns tipos de análise de conteúdo que constituem, às vezes, um tipo de receita mecânica". Em sua opinião, o que quer dizer "receita mecânica”?

DD - Bom, quer dizer que discutimos, em particular, a análise proposicional do discurso, que é, de fato, uma espécie de receita mecânica, no sentido de que há um certo número de regras formais que são aplicadas ao corpus das entrevistas das quais decorrem resultados que talvez fossem mais de programas de computação (softwares) 
de análise textual automatizada, ${ }^{13}$ por exemplo, que vão também nesse sentido e, para mim, não me parece que é um método ruim, mas é preciso reintroduzir reflexividade.

Em contrapartida, mais recentemente, coordenei um livro sobre os softwares de análise textual em que, na introdução, tento defender o fato de que há duas coisas que contam na análise dos materiais discursivos, como são, por exemplo, as entrevistas. Uma primeira coisa é ter um certo número de princípios, que não são princípios técnicos, mas, sim, teóricos, e podem ser depois traduzidos em elementos técnicos, digamos, em operações elementares.

Um princípio teórico fundamental, por exemplo, é dizer, a exemplo de Greimas, que o sentido é diferencial. Eis aqui um princípio teórico, isto é, se alguém lhe disse: "encontrei uma boa colocação, um bom emprego". Bom, isso não quer dizer nada. Para que se compreenda o que ele quis dizer, é preciso identificar que situação, que é designada como "um bom emprego", é comparada pelo indivíduo. O que faz com que seja um bom emprego? É um bom emprego porque antes eu tinha um emprego que não era da minha profissão ou, então, um emprego precário.

Num caso como no outro, o "bom emprego" não tem o mesmo sentido, remete ao universo da profissão, dos saberes ou, então, ao universo da estabilidade, da segurança.É preciso ter princípios teóricos desse tipo e dizer que o sentido é diferencial. Isto é, por exemplo, um princípio teórico da maior importância. Então, isso é uma primeira coisa. São necessários alguns princípios como esse, que, no entanto, não fornecem receitas de análise.

E a segunda é que é preciso reflexividade. Isto é, é preciso que o pesquisador reflita sobre o que ele está fazendo e a melhor maneira de fazê-lo é não analisar sozinho as entrevistas. Porque sendo dois ou até mais... embora, se forem muitos é mais complicado... Acho que o número ideal é de dois ou três... isso obriga cada um a explicitar, de fato, o que entende e a argumentar, apoiando-se em dados, para explicar ao outro, o que ele entende.

VM - Caso contrário, é uma análise subjetiva. Podemos dizer assim?

DD - É isso, subjetiva. Isto é, eu projeto minha interpretação.

13 Trata-se de programas que fazem a análise por meio de contagem das frequências das palavras e expressões. "Ele analisa textos automaticamente e calcula graus de utilização de grupos de palavras e categorias que uma pessoa usa em variados tipos de textos, como e-mails, discursos, redes sociais, poemas, notícias". Disponível em: <http:// cetorres.com/2010/12/analise-textual-pode-descobrir-sua-personalidade-nas-redessociais/>. Acesso em: maio 2011. 
VM - Para você, a colocação é boa e para mim não, ela não é boa. É isso?

$\mathrm{DD}$ - Ou, então, uma análise mecânica. Isto é, existem receitas como, por exemplo, os softwares, tratamentos por softwares que lhe dizem, pronto! Aqui estão seus resultados de análise. Como se o pesquisador não produzisse resultados, deixasse isso por conta do software. Então, é preciso ficar entre os dois. É bem essa a ideia do livro. A ideia do livro não é dizer: pronto! Eis aqui um bom método! Mas dizer, no conjunto dos possíveis encaminhamentos: vamos evitar o subjetivismo que consiste em projetar nossas próprias categorias que sequer são categorias sociológicas, que são categorias subjetivas. Evitemos também o tipo de ilusão que consiste em dizer: já que existe um software ou um método formal, então, atingimos uma espécie de verdade de análise. Não se trata de uma operação principalmente técnica, mesmo se há uma dimensão técnica. Porém, não é principalmente técnica; então, essa é uma ideia central no livro.

$\mathrm{VM}$ - Eu li, notei isso, percebi que uma de suas pesquisas atuais é sobre os softwares, é isso?

DD - Sobre os softwares? Sobre os softwares livres, ${ }^{14}$ não é?

$\mathrm{VM}$ - E seu interesse começou lá, quando teve esse tipo de inquietação? Ou não necessariamente?

DD - Não, meu interesse partiu de algo completamente diferente. Na realidade... Digamos que desde minha tese trabalhei muito, por um lado, sobre as questões de desemprego, de emprego, de inserção no mercado de trabalho, em particular pelo ângulo das biografias, com as entrevistas etc. E, em parte, porque fiz coisas sobre a avaliação das políticas públicas de emprego, mas, enfim, apesar disso, essencialmente pelo ângulo biográfico.

E em 2000, mais ou menos naquela época, 2000 ou 2001, assumi a direção do laboratório Printemps, que é um laboratório que tinha como vitrine científica, isto é, como elemento de especialidade, por um lado, os métodos de análise longitudinal, poderia ser dito os métodos de análise das carreiras biográficas, ao mesmo tempo, estatísticos e qualitativos. E, por outro lado, a sociologia das profissões. E eu não estava de jeito nenhum na sociologia das profissões, mesmo que tivesse trabalhado um pouco para os conselheiros da agência pelo emprego.

14 Softwares livres são programas de computação utilizados gratuitamente. Geralmente, quando esses programas não são acessados de maneira gratuita, ou seja, são comprados comercialmente, apresentam um custo elevado, o que dificulta a aquisição por pesquisadores isoladamente. Por isso, são adquiridos em editais das agências de fomento à pesquisa e utilizados por vários pesquisadores envolvidos em um mesmo laboratório de pesquisa. 
Ao assumir a direção do laboratório, decidi dedicar-me a esse campo da sociologia das profissões. Parecia-me que era algo novo na França e era importante jogar essa carta para fazer crescer a reputação desse laboratório, o seu reconhecimento. Comecei, então, a me engajar numa série de trabalhos. De início, encorajei o desenvolvimento de trabalhos sobre as profissões no cerne do laboratório e, pessoalmente, dei início a uma série de trabalhos sobre... diria que sobre as profissões problemáticas, isto é, não os ofícios bem delimitados, bem objetivados, bem claros, bem estabelecidos, bem reconhecidos, mas as atividades profissionais especializadas que não são bem estabilizadas, não são legitimadas.

$\mathrm{E}$, nesse quadro, comecei a pesquisar sobre os profissionais que produzem softwares livres. O que me interessava nisso era o fato de que essa atividade de produção era realizada por indivíduos autônomos, isto é, não remunerados. Comparando com uma atividade profissional habitual, não há contrato de trabalho. Em segundo lugar, esse trabalho de produção está inserido em organizações atípicas, curiosas, já que elas funcionam com o princípio da recusa de toda hierarquia. Comparando com uma organização habitual, em que há gestores, uma hierarquia que dá ordens, que controla as atividades etc., lá, isso não existia. Portanto, isso me interessou por ser um caso-limite, digamos, da atividade profissional, e foi por isso que me interessei sobre esse setor dos softwares livres.

Em contrapartida, isso me permitiu continuar trabalhando com o método das entrevistas biográficas sem deixar de desenvolver métodos etnográficos um pouco peculiares, já que esses grupos de produção se parecem com analistas de sistemas que estão espalhados geograficamente. Estão presentes nos Estados Unidos, na Hungria, na Bélgica, na França e, então, existem questões de coordenação quando se trabalha dessa maneira, de maneira esfacelada, dispersa, quando não se tem chefe, quando não se tem contrato de trabalho, que os compromissos têm por base a condição de autônomo.

É uma questão que me atraía, e me interessava ver como é que se pode observar o trabalho individual e coletivo dessas comunidades e, então, desenvolver métodos etnográficos específicos para essa forma de trabalho. É isso, é por isso que desde então... Comecei lá meus primeiros trabalhos, penso eu, em 2005 talvez, e desde então continuei trabalhando nessa questão sem deixar de trabalhar também sobre outros assuntos. Digamos, eu trabalho nessa questão numa perspectiva de longa duração.

VM - Certo. Bom, ainda sobre o livro, o que pensa, agora, depois de quase dez anos que o livro foi reeditado, da situação do desemprego entre os jovens. Ela mudou muito? Ela melhorou? Ela cresceu? O que está ocorrendo entre os jovens diplomados e não diplomados? 
DD - Em primeiro lugar, o elemento de estabilidade é que os jovens são sempre, desde o fim dos anos de 1970, a categoria etária mais vulnerável ao desemprego. É ali que existe desemprego maciço, taxas de desemprego mais elevadas que as taxas médias etc. Isso é a primeira coisa. Porque o mecanismo clássico é que, quando já se está presente no mercado de trabalho, as possibilidades de ficar desempregado são mais fracas que quando se está fora. $\mathrm{E}$ o que caracteriza os jovens é que eles saem da escola, qualquer que seja seu nível de estudo, e procuram um emprego, portanto, eles estão fora.

Então, esse fenômeno que desfavorece os jovens é constante, e atualmente existe um plano governamental que vai ser lançado... Falaram dele ainda esta semana na França, um grande plano que vai ser lançado para justamente fazer do desemprego dos jovens uma grande causa nacional. Mas é também isso que vimos com bastante regularidade nos últimos trinta anos. Isso é o primeiro ponto. O segundo ponto, que continua sendo um elemento permanente, é que a exposição dos jovens ao desemprego é distribuída em razão do nível dos diplomas. Os que não têm diploma são os que conhecem as mais elevadas taxas de desemprego, e são aqueles que fizeram estudos superiores que conhecem as mais baixas taxas.

Bom, a hierarquia é essa, grosso modo. Essa hierarquia permanece mais ou menos idêntica. Agora, se olharmos para a situação, é verdade que, nos últimos quinze anos, o desemprego dos diplomados do ensino superior tendeu a aumentar, particularmente, em certos tipos de formação.

VM - Sim. Vemos esses dados nas pesquisas sobre gerações dos anos de 1998, 2001, 2004 e, agora, a de 2007, do CEREQ.

DD - Absolutamente!

VM - Há mestres, doutores e também graduados desempregados.

DD - É isso mesmo!

VM - Mas isso é em todo lugar. A situação é a mesma na França, na Bélgica, no Brasil... É por toda parte, em diferentes níveis?!

DD - Mas é num contexto em que há uma elevação geral dos níveis de diplomas. É preciso ver que o número de doutores ou de mestres, que saem do sistema educativo a cada ano, é evidentemente muito mais elevado hoje que em 1995 ou 1985. Há mais concluintes do sistema escolar com esses diplomas. Isso tem, de fato, efeitos mecânicos sobre o mercado de trabalho, porque a evolução da estrutura dos empregos é independente da estrutura dos diplomados. Então, os desníveis se 
aprofundam. E, ainda por cima, há o crescimento do desemprego, ligado em parte ao aumento do tempo necessário para encontrar uma inserção profissional, e depois, ainda, o sintoma de problemas no mercado de trabalho para os diplomados. Isso é um fenômeno mais recente.

VM - Sim, esse é o tema que pesquiso!

DD - Sim, eu sei. Exatamente.

VM - Da minha parte, estou terminando a entrevista. Sei que você pesquisa atualmente sobre os softwares, sobre os políticos eleitos e também sobre os agentes de jogadores de futebol. Imagino que há muita precariedade entre eles... Não há? Como trabalham? Há regras ou não há?

DD - Bom, lá também se trata de um caso empírico, digamos daquilo que chamo de profissão problemática, mas num outro sentido que para os criadores de softwares livres, ou seja, é uma profissão muito estigmatizada, desvalorizada, como se os profissionais fossem uma espécie de parasitas que ganham muito dinheiro, um dinheiro com fama de fácil, quando incitam os jogadores a mudar de time. Sem entrar em detalhes, a situação do futebol, vinte anos atrás, era a de que os jogadores faziam carreira com menos mobilidade. Ao longo de sua carreira, os jogadores passavam por dois ou três times, ou seja, quando entravam num time, ficavam nele por cinco, seis, sete anos. E o fenômeno que mudou é que esses períodos são muito mais curtos. Eles permanecem dois, três anos e vão passar por seis ou sete times ao longo da carreira.

Os agentes têm como papel, entre outros, negociar as transferências e aconselhar os jogadores. E, assim, eles foram estigmatizados como sendo responsáveis por essa mobilidade cada vez mais intensa dos jogadores. Na realidade, tudo isso se deve a outro fenômeno, que é o fato de haver cada vez mais dinheiro no futebol e de os times proporem condições salariais melhores aos jogadores. Então, se um jogador receber 100 mil euros mensais hoje e se lhe oferecem 350 mil euros em outro lugar, com a incitação do agente ou não, são grandes as chances de ele dizer: "sim, é uma boa oportunidade, não devo perdê-la”. Porém, é uma profissão que tem uma reputação muito ruim.

Isso é o primeiro ponto. $\mathrm{O}$ segundo ponto é que se trata de uma profissão regulamentada, porque, para ser agente de jogador, para ter a autorização de ser agente de jogador e, portanto, representar jogadores nas negociações de transferência, é preciso ter uma licença que é atribuída pelas federações de futebol. E para obter essa licença é preciso ter sido aprovado num exame em que são avaliados, basicamente, os conhecimentos jurídicos: direito trabalhista, direito fiscal, direito comercial etc. 
$\mathrm{Na}$ França, a taxa de aprovação é baixa, ela flutua anualmente entre $7 \%$ e 12\%. Isso quer dizer que é muito seletivo. Então, o número de agentes na França permanece limitado, atualmente são aproximadamente 250 porque não se pode ser agente sem ser aprovado nesse exame. Mas 20 desses 250 são os que gerem em torno de $70 \%$ ou $80 \%$ das transferências e são muito ricos. Depois vêm os outros, uma grande parte não tem quase atividade, não consegue ter contrato com nenhum jogador. Eles não têm jogadores, eles não conseguem negociar contrato para ninguém. $\mathrm{E}$ há outra fração que consegue viver, com mais ou menos dificuldade, negociando de vez em quando uma transferência, procurando sobretudo detectar os jovens jogadores promissores, para acompanhá-los na sua carreira. Mas eles raramente negociam transferências importantes que correspondem ao território da minoria, dos "grandes" agentes.

Então, é uma profissão muito hierarquizada, com uma situação de quase monopólio, detida por uma pequena minoria que se beneficia com uma rede relacional muito importante no meio futebolístico. Assim, por consequência, o que condiciona o exercício da profissão de agente é menos o exame e mais o fato de pertencer à rede do meio. Um bom jurista que é aprovado no exame, se ele não tiver uma boa rede social no meio futebolístico, não poderá exercer sua profissão de agente. É isso, é uma profissão formalmente regulamentada, porém, regulada completamente por outros princípios. E essa questão das redes sociais no futebol é evidentemente, quaisquer que sejam as características delas, a seguinte: de onde vêm?

Evidentemente, existe toda uma série de representações mais ou menos fantasiosas quanto ao fato de que os grandes agentes pertencem a máfias e por aí vai. Digo "mais ou menos fantasiosas" porque é verdade que de vez em quando ocorrem escândalos, já que há muito dinheiro circulando e, consequentemente, complementos de honorários sobre os montantes das transferências são enviados para contas nas Ilhas Cayman etc. E, de vez em quando, ocorrem escândalos desse tipo. Mas, em compensação, a maior parte das transferências segue circuitos financeiros identificáveis e legais.

Em tal caso, um aspecto da pesquisa é tentar compreender como funciona o sistema de transferências e, sobretudo, identificar como os agentes conseguem constituir e conservar um portfólio de jogadores, já que, de fato, para ter sucesso, o agente deve ter um contrato com os jogadores, caso contrário, ele não pode negociar transferências. E ele precisa ter jogadores que vão custar caro, então, como isso se faz entre os agentes e os jogadores? É uma das dimensões que estudamos neste trabalho; e isso remete a uma articulação entre um mercado profissional, o dos agentes e o mercado de trabalho dos jogadores de futebol.

VM-Muito interessante! E esse tipo de pesquisa é feito no CNRS ou na Sciences Po? 
DD - Na realidade, é uma pesquisa que comecei, como as outras, aliás, antes de chegar a Sciences Po e com financiamentos que obtive quando eu ainda não estava lá. São financiamentos geridos pelo CNRS. Mas, de fato, tenho um contrato, posso escolher entre fazer com que sejam geridos pelo Sciences Po ou pelo CNRS. Mas é equivalente.

$\mathrm{VM}-$ É igual?

$\mathrm{DD}$ - É igual e, de toda maneira, no que se refere à minha assinatura, devo assinar pelo CNRS e também pela Sciences Po. Essas são as regras, uma vez que o CNRS é meu empregador, sou pago pelo CNRS, mas a Sciences Po é o estabelecimento de ensino ao qual o laboratório, isto é, o CSO pertence. Então, há regras para a assinatura.

VM - E imagino que gosta de futebol. Vejo na sua mesa uma xicarazinha de café do Barça (Barcelona). Então, vamos ver o que acontecerá logo mais? $?^{15}$

DD - Sim, adoro futebol e sou torcedor, desde garoto, do time de Lille, o LOSC. $\mathrm{E}$ atualmente o LOSC é líder do campeonato. Mas, para hoje, eu me vesti de verde e amarelo!

VM - Sim, eu percebi, o verde e o amarelo. Isso é bom!

DD - Sim, estou completamente de amarelo e verde, mas, hoje à noite, vou torcer pela França.

VM - Então, amanhã lhe mando um e-mail para dar-lhe os parabéns ou os pêsames. Certo?

DD - Três a um para o time da França

VM - Não sei... Bom, isso era tudo o que tinha vontade de lhe perguntar. Tem alguma coisa a acrescentar?

DD - Mais alguma coisa?!

VM - Foi difícil? Foi pesado?

15 Naquela noite (9 de fevereiro), houve um jogo em Paris entre a França e o Brasil. Infelizmente, o resultado foi: França $1 \times 0$ Brasil. 
DD - Não. Bom, não foi pesado, não foi duro de jeito nenhum, poderia falar durante horas. Não, se você pensa que obteve as informações que lhe interessam, é isso!

VM - Para mim está bom. Penso que vou fazer a transcrição e depois lhe mando. Obrigada pela sua atenção.

\section{REFERÊNCIAS}

Bianchetti, Lucídio; Mattos, Valéria. A expansão da educação superiror na Europa: análise de impactos do Tratado de Bolonha.In: Catani, Afrânio Mendes et al. (Orgs.). A cultura da universidade pública brasileira. Mercantilização do conhecimento e certificação em massa. São Paulo: Xamã, 2011. p. 65-93.

Demazière, Didier. La sociologie du chomage. Paris: La Découverte, 1995.

.Uma abordagem sociológica sobre a categoria do desemprego. In: GuIMArães, Nadya Araújo; Hirata, Helena (Orgs.). Desemprego: trajetórias, identidades, mobilizações. São Paulo: SENAC, 2006a. p. 23-42.

. Sociologie des chômeurs. Paris: La Découverte, 2006b. (Collection Repères).

.; Dubar, Claude. L'entretien biographique comme outil de l'analyse sociologique. Revue de Sociologie et d'Anthropolie (UTINAN). Dynamiques professionnelles et temporalités, Paris, L'Harmattan, p. 225-239, 1999.

. Analyser les entretiens biografiques. L'exemple des récits d'insertion. 2. ed. Paris: Presses de L'Université Laval, 2004.

Guimarães, Nadya Araújo. Desemprego, uma construção social. São Paulo, Paris, Tóquio. Belo Horizonte: Argumentum, 2009.

.; Hirata, Helena (Orgs.). Desemprego: trajetórias, identidades, mobilizações. São Paulo: SENAC, 2006.

Recebido em maio de 2011

Aprovado em setembro de 2011 